\title{
Invited review: A systematic literature review and meta-analysis of mortality and culling in dairy cattle
}

\author{
C. W. R. Compton, ${ }^{1}{ }^{1}$ C. Heuer, ${ }^{*}$ P. T. Thomsen, $\dagger$ T. E. Carpenter, ${ }^{*}$ C. V. C. Phyn, $\ddagger$ and S. McDougall \\ *Epicentre, Institute of Vet, Animal and Biomedical Sciences, Private Bag 11 222, Massey University, Palmerston North 4442, New Zealand \\ †Department of Animal Science, Aarhus University, PO Box 50, DK-8830 Tjele, Denmark \\ ‡DairyNZ, Private Bag 3221, Hamilton 3240, New Zealand \\ §Cognosco, Anexa FVC Morrinsville, PO Box 21, Morrinsville 3340, New Zealand
}

\section{ABSTRACT}

Dairy industries and individual farmers are concerned about mortality and culling of dairy animals. This is because the timing and fates of animals that exit dairy farms have important animal welfare and economic consequences that reflect the conditions under which they are farmed and the efficiency of their production systems. Reports from a few countries have indicated increased incidence of mortality, and occasionally culling, of dairy animals in recent decades, and these changes have been associated with intensification of production systems. Dairy industries and farmers need benchmarks for culling and mortality against which they can compare themselves, as well as improved understanding of the extent of any change and of any associated factors. We reasoned that a systematic literature review and meta-analysis of scientific articles published between 1989 and 2014 would allow us to determine whether these reports were universal, to quantify any change over time, and to investigate whether production systems or study factors were associated with culling and mortality. From 3,275 articles retrieved from databases and manual searching of cited articles, 118 articles were appraised independently by 2 assessors, and 51 articles representing 54 studies were determined to be eligible for review and meta-analysis. We estimated that both the annual incidence risk (IR) and incidence density of mortality of cows had increased significantly from 0.02 per cow and 2.32 per 100 cow-years, to 0.04 per cow and 3.75 per 100 cow-years, an increase per decade of 0.02 per cow and 1.42 per 100 cow-years, respectively. We also estimated that the annual IR of culling attributed to low production had declined significantly from 0.07 to 0.05 and that the IR of perinatal, but not neonatal, mortality had increased significantly from 0.04 to 0.06 per decade. We found no evidence

Received April 10, 2016.

Accepted September 4, 2016.

${ }^{1}$ Corresponding author: C.W.Compton@massey.ac.nz of change in overall annual IR of culling of cows over time or any association between study design factors and the IR or incidence density of culling or mortality. These findings provide benchmarks for describing culling and mortality, and should encourage farmers and researchers in countries with modern dairy industries to discover and implement management strategies to reduce the animal welfare and economic costs associated with these changes.

Key words: dairy cow, dairy replacement, culling, mortality

\section{INTRODUCTION}

Culling or mortality is inevitable for all dairy animals, as they must ultimately exit the herd for slaughter or sale or die on-farm. Thus, although these events are inevitable and common, understanding their extent and causes at the herd or industry level is challenging because culling and mortality are influenced by economic, social, management, and animal disease factors. In turn, culling and mortality have important economic and animal welfare consequences. Net farm revenue is affected by costs incurred from rearing and purchase of replacements, and milk income is affected by replacement rate because, on average, replacements produce less milk than the animals they replace (Renkema and Stelwagen, 1979; Rogers et al., 1988). High and sustained rates of culling and, in particular, mortality, are also indicators of poor welfare status (de Vries et al., 2011). For these reasons, an accurate quantitative description of culling and mortality within and across different dairy production systems provides a foundation for understanding, extension, and further research.

Several authors have reported an increased incidence of mortality and, occasionally, culling over the last 2 to 3 decades in dairy production systems in North America and Europe. For example, Thomsen et al. (2004) concluded that the lactational incidence risk (IR) of mortality of dairy cows in Denmark had increased between 1990 and 2001, and De Vries et al. 
(2010) reported increased culling rates in large dairy herds in the eastern United States between 2001 and 2006. Furthermore, an increase in the incidence density (ID), sometimes known as the incidence rate of mortality, in Swedish cows was associated with intensification of that industry, as measured by increased herd size and average per cow milk production (Alvåsen et al., 2014b). However, it is unknown whether these reports are representative of other regions or countries, but we reasoned that these reported changes would also be reflected in other countries that have increased milk production and herd size in recent decades.

Development of control programs to mitigate against any such changes will require that they are quantified and, where it is valid to do so, knowledge of contributing causes of culling or mortality transferred between production systems. Systematic reviews (SR) and meta-analyses (MA) are methods suited to provide this information. They aim to review and summarize primary (original) literature on a topic (Sargeant and O'Connor, 2014; O'Connor and Sargeant, 2015) to provide a readily available source of information on which to base actions in the practice of evidence-based medicine or to direct policy decisions (O'Connor and Sargeant, 2014). Systematic reviews and MA of observational studies are less common than those for randomized clinical trials, in part because of the inherent biases and differences in study methods used by epidemiological researchers (Egger et al., 1998). However, MA can not only provide summary measures of, for example, prevalence of a disorder, but also investigate by using meta-regression (MR), the effect of moderator variables, such as study population characteristics or design features, on the results. We reasoned that we might identify, by the use of MR, a positive association between the incidence of culling and mortality and both the year of data collection in reviewed studies and measures of intensification of production systems, such as mean per cow milk production and herd size.

The main aim of this SR-MA was to investigate any change in the incidence of mortality or culling of dairy animals, reported in population-based studies from modern production systems and published between 1989 and 2014. We also aimed to determine if the incidence was modified by changes in production systems and whether study design features affected the results reported.

\section{MATERIALS AND METHODS}

\section{Scope of Review}

Only articles from countries with modern dairy production systems were considered, because results of a preliminary database search of scientific articles were mainly from these countries, and other systems were considered so dissimilar that results from others could not be reasonably compared. For this review, countries with modern production systems were defined as those that typically farmed Holstein-Friesian, Norwegian Red, Brown Swiss, Ayrshire, or Jersey dairy breeds (pp. 130 to 131 in FAO, IDF, and IFCN, 2014), and included mainly countries in the European Union, North and South America, and Australasia. The publication period was chosen to allow sufficient duration to allow us to identify any change. The outcome measures we considered were the IR and ID of mortality and culling, and length of productive life (LPL). Sale of animals was not specifically considered, except where it was combined with culling, mortality, or both, and the categories could not be separated. This was because sale of animals for further productive purposes was considered an economically favorable choice made by the owner, and sale has few adverse effects on the welfare of animals. Only female dairy animals were considered in this review, except for the results of perinatal mortality, where data from these studies usually reported both male and female calves combined.

\section{Definitions}

The main outcomes and definitions were culling (removal of a live cow from the farm for immediate slaughter), sale (movement to another farm for future dairy purposes and assumed to exclude temporary ownership by traders who subsequently send animals for slaughter), and mortality (death of an animal on the farm, whether euthanized or unassisted). The use of these terms varied among articles in this review but, where possible, their findings were categorized according to these definitions so they were comparable.

The definitions of the outcome measures used to quantify culling and mortality varied among articles. The definitions we used for IR and ID were those commonly applied in epidemiological studies (Dohoo et al., 2009 , p. 77$): I R=\frac{X}{N}$, where $X$ is the number of newly affected individuals in a defined period and $N$ is the number of animals in the population at risk of the condition; and $I D=\frac{X}{T}$, where $X$ is as defined for IR and $T$ is the number of animal-time units at risk during the observed period. The definition of LPL was the interval (days) between first calving and culling or death.

The age categories for animals used for description of articles in the SR were calves (preweaned), heifers (weaning to age at first calving), and cows (calved at least once). Calves were further categorized for MA-MR 
as perinatal (full-term birth to d 2 of life) or neonatal (d 1 of life to weaning). Sufficient data were available on causes attributed to culling of cows to be grouped into the 3 most frequent categories: udder-related (mastitis, high SCC, teat injuries), reproduction (not pregnant, reproductive disease causing infertility), and production (low milk production).

\section{Identification of Literature for Review}

Literature Search. The electronic literature databases searched were Web of Science (http://wokinfo. com, including $\mathrm{CAB}$ Abstracts, Medline, Biological Abstracts, Web of Science Core Collection) and Scopus (www.scopus.com). These databases were chosen because they have high coverage rates of veterinary journals and others with significant veterinary content (Grindlay et al., 2012). Scientific articles (both peer-reviewed and non-peer-reviewed) and conference proceedings written in English; or written in Spanish, French, or German, if their title or abstract were in English; were eligible for appraisal. The literature search ceased in December 2014. The population search terms were dairy, cattle, calf OR calves, replacement, heifer OR heifers, cow OR cows, bovine. The outcome search terms were lifetime OR life-time OR survival OR survivorship OR culling OR removal OR death OR dead OR died OR loss OR fatality OR mortality OR euthanasia OR euthanized OR sale OR sold OR loss OR longevity OR disposal OR stayability OR productive life OR functional life.

Screening and Appraisal of Articles. Primary screening of articles was based on information in the title and abstracts to answer 3 questions: Are the words in the title or abstract, or both, directly related to or included in the main study aim? Does the title or abstract, or both, describe an original research study (as opposed to a review)? Was measurement of an outcome of interest (e.g., mortality, culling) an important objective of the study? Only articles with a positive response to all 3 questions were eligible to proceed to the next stage. Primary screening of every article was undertaken by the first author (C. W. R. Compton) and the reasons for inclusion and exclusion and their frequency summarized using a flowchart. Additionally, a manual search was undertaken in articles passing the primary screen of further articles cited by their authors. The search strategy was assessed by checking references from the 10 most recent articles on the topic and checking against articles identified by the search strategy, and by checking the 10 oldest articles and citation-searching forward.

Where 2 or more companion articles reported on the same study, the year of publication of the last-published paper was taken as the year for deciding on inclusion. In cases where a study published in a non-peer-reviewed source was also published in a peer-reviewed source, the latter was preferred for assessment. Where 2 articles reported the same study, the earlier published article was preferred, except where additional new material was provided in the later article, in which case it was considered independently. Articles that focused on risk factors for culling or mortality were considered where incidence or productive life were also reported.

During secondary screening of articles, we aimed to appraise how completely the methods were described and the risk of bias in the results arising from the design and conduct of the study. The appraisal tool used to assess each article for inclusion in the review was in the form of a checklist (Supplemental Table S1; https://doi.org/10.3168/jds.2016-11302) and was based on those of Sargeant and Del Rocio Amezcua (2005) and Sanderson et al. (2007). Most elements required a "yes" or "no" response, except for some for which a "not applicable" response was possible because the element was not relevant. Finally, the reviewers indicated whether the article was eligible for inclusion in the review. The article appraisal tool was pretested by all reviewers on 6 articles and minor modifications made to the responses allowable for some questions. Each article was appraised by 2 reviewers (C. W. R. Compton and P. T. Thomsen), except where a reviewer was also an author of the article. In these cases, and when differences occurred between the first 2 reviewers as to eligibility, a third reviewer (C. Heuer) appraised the article, and the majority finding was final.

Studies not excluded at the primary or secondary screening formed a preliminary final set of articles for review. The authors of articles from which additional data were required for meta-analysis were contacted and these data requested. Articles that did not require additional data and those for which an author provided the requested data formed the final set of articles for review.

\section{Data Management}

The year the results were collected in was included as a continuous variable in the MR models. When data were collected over more than $1 \mathrm{yr}$ and annual results were not available, the results were combined and the median year of data collection used for MA-MR. Study design characteristics (Table 1) were used as possible moderator variables in subsequent $\mathrm{MR}$, and were categorized by their type (prospective, retrospective, cross-sectional), the main aim of the study (descriptive, analysis of risk factors, or a combination of both), the sample selection method (census, convenience, random- 
ized, restricted by design, self-selection, or a mixed selection method), the source of the data (primary; i.e., actively collected by the researcher for the purpose of the study, or secondary; i.e., data originally collected for other purposes), and the persons responsible for attributing the cause of culling or mortality (farmer, veterinarian, or results from a necropsy).

The data required for MA-MR depended on the outcome measure. For IR, we extracted both the number of cases in the defined period and the number of animals in the population at the start or end of the observation period. For ID, we extracted both the number of cases in the defined period and total animal-time at risk. For LPL, both the mean and standard deviation were required. When the data available in an article were not immediately suitable for meta-analysis, they were reconstructed. For example, when the IR of culling was reported as a percentage, and the population at risk was known, then the number culled was the multiple of the IR and the population at risk. When an IR was reported with a standard error (e.g., the USDA, 2007 report), the standard error of the IR (a proportion, $p$ ) was used to estimate the number of animals at risk $(n)$ by rearranging the formula $S E_{p}=\sqrt{\frac{p \times(1-p)}{n}}$ to $n=\frac{p \times(1-p)}{S E_{p}^{2}}$; and the number of culls was estimated as described previously. When we could not reconstruct data for meta-analysis, we requested additional data from the authors of the articles. Where these data were provided, those studies were included in the meta-analysis; otherwise, they were excluded.

Data on the attributed causes of culling or mortality were only considered for meta-analysis when the IR or ID for that particular cause was either reported or could be reconstructed from the data. In this way, comparisons between the findings of different studies were possible, which is not the case when causes of removal are only reported as proportions without an overall population incidence.

Extracted data were entered into and managed in a custom-built Access database (version 2010, Microsoft Corp., Redmond, WA).

\section{Analytical Methods}

Bias Assessment. The results of the qualitative assessment of 4 elements from appraisal of the articles (Supplemental Table S1, elements 2a, 4a, 4b, and 5a; https://doi.org/10.3168/jds.2016-11302) relevant to selection or information bias were used to form a composite score to assess the risk of bias in each article.
Table 1. Summary descriptive statistics of design features (n) of 54 studies from 51 articles $(\mathrm{N})$ included in a systematic review and metaanalysis of culling and mortality in dairy animals

\begin{tabular}{lrl}
\hline Feature & $\mathrm{n}(\%)$ & $\mathrm{N}$ \\
\hline Study design & \\
Cross-sectional & $1(2)$ & 54 \\
Prospective & $17(31)$ & \\
Retrospective & $36(67)$ & \\
Data source & $1(2)$ & \\
Mixed & $24(44)$ & \\
Primary & $29(54)$ & \\
Secondary & $12(22)$ & \\
Sample selection method & $6(11)$ & \\
Census & $1(2)$ & \\
Convenience & $9(17)$ & \\
Mixed & $25(46)$ & \\
Random & $1(2)$ & \\
Restricted & & 54 \\
Self-selected & $12(22)$ & \\
Denominator definition & \\
ID Std & $20(37)$ & \\
IR Std & $2(4)$ & \\
IR StrtMinHlfRm & $6(11)$ & \\
IR Avg & $3(6)$ & \\
IR PdEndInvnt & $5(9)$ & \\
IR PdClvd & $5(9)$ & \\
NotApplic & $1(2)$ & \\
IR PdLctEnd & $12(24)$ & 51 \\
Data validated & $5(10)$ & 51 \\
Causes of exit defined & \\
\hline
\end{tabular}

${ }^{1}$ Cross-sectional $=$ measurements made at a single point in time; Prospective = measurements taken as time progressed during study; Retrospective $=$ measurements taken before start of study.

${ }^{2} \mathrm{ID}=$ incidence density; IR = incidence risk; ID Std = sum of animaltime in risk period; IR Std = number of animals at start of risk period; IR StrtMinHlfRm = number of animals at start less half of the animals removed in the risk period; IR Avg = average number of animals in the risk period; IR PdEndInvnt $=$ number of animals at the end of the risk period; IR PdClvd = number of cows that calved in the risk period; NotApplic $=$ not applicable as not a ratio measure (e.g., productive life); IR PdLctEnd = number of animals ending a lactation in the risk period.

Individual reviewer appraisal scores for the risk of each element to contribute to bias were on a binary scale ("no" or "yes"). When there was agreement between the reviewers, that finding was reported; otherwise, the finding was "unclear."

Meta-Analysis and Meta-Regression. Separate MA-MR were undertaken for each combination of alike outcome, outcome measure, and age or parity group, using $\mathrm{R}$ statistical software (version 3.2.2.; R Foundation for Statistical Computing, Vienna, Austria) and the R package "metafor" version 1.9-7 (Viechtbauer, 2010). The main outcome measures (IR or ID) were calculated for each study and double arcsine transformed (Freeman and Tukey, 1950) to stabilize their variances for meta-analysis and meta-regression. Point estimates and confidence intervals were transformed for display in forest plots. Symbol sizes of the study estimates were drawn in proportion to their precision, and thus de- 
pendent on sample size. We used random mixed effects models for meta-regression because we wanted to make an inference from the results to a larger set of studies, from which the studies included in the current MA-MR were assumed a random sample (Hedges and Vevea, 1998). Data from studies that reported multiple years of results were considered correlated. For these results, a separate random effect term for each study-year with a compound symmetry correlation structure was added (Konstantopoulos, 2011). An aim of the analysis was to investigate the effect of study-level moderator or predictor variables on the outcomes, and hence these factors were added to build MR models. Mathematical notation of the 3-level meta-regression model with $p$ predictors included at the second level is shown as

$$
\vartheta_{i g}=\beta_{0 g}+\beta_{1 g} X_{1 i g}+\ldots+\beta_{p g} X_{p i g}+\eta_{i g}+e_{i g}
$$

where $\vartheta_{i g}$ is the unknown IR or ID, which varies around a level-3 unit $g$ mean, $X_{1 i g}, \ldots, X_{p i g}$ are study-specific predictors (e.g., year of data collection), $\beta_{0 g}, \beta_{1 g}, \ldots, \beta_{p g}$ are unknown regression coefficients that need to be estimated, $\eta_{i g}$ is a level-2 random effect term with distribution $N\left(0, \tau^{2}\right)$, and $e_{i g}$ is the level-1 error term with distribution $N\left(0, v_{i}\right)$, where $\tau^{2}$ is the residual variance, and $v_{i}$ is the variance of the effect size estimate. The level-3 unit means are estimated from the overall mean and level-3 unit specific random effects: $\beta_{0 g}=\gamma_{0 o}+\nu_{0 g}$, where $\gamma_{0 o}$ is the overall mean and $\nu_{0 g}$ is the level-3 unit random effect.

The effect of possible moderator variables and the level-2 random effect term were examined in each model by manual forward stepwise addition, and were retained when Wald-type and likelihood ratio tests, respectively, for their addition, were significant $(P<$ $0.05)$. Plots of influential studies were available for each simple random effects model, and these were assessed by visual inspection of the studentized residuals and Cook's distances, for the effect of individual studies on heterogeneity and model fit, respectively. Influential

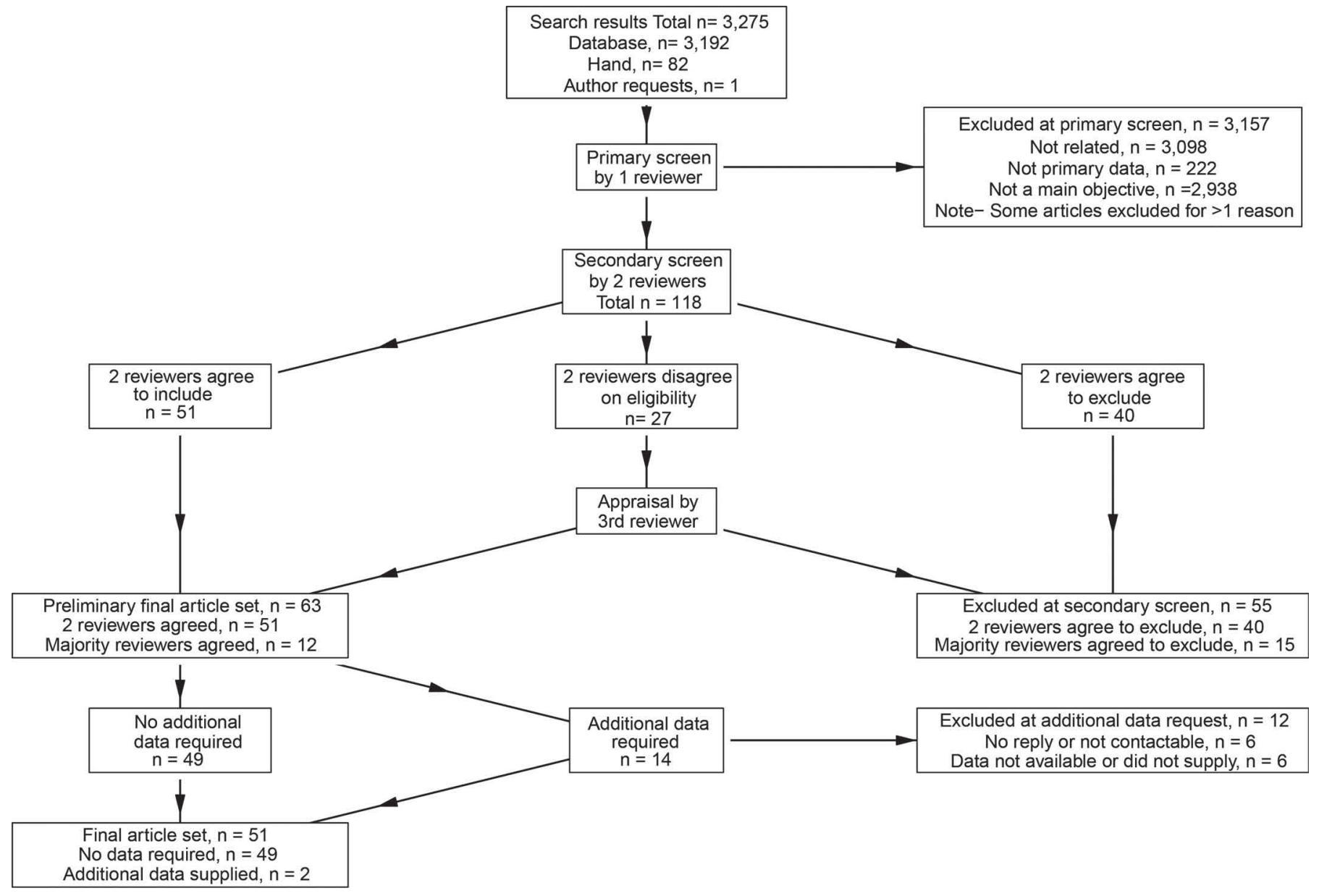

Figure 1. Flowchart of selection of articles for systematic review. 
Table 2. Summary of 54 studies from 51 articles included in a systematic review and meta-analysis of culling and mortality in dairy animals, sorted by year of publication

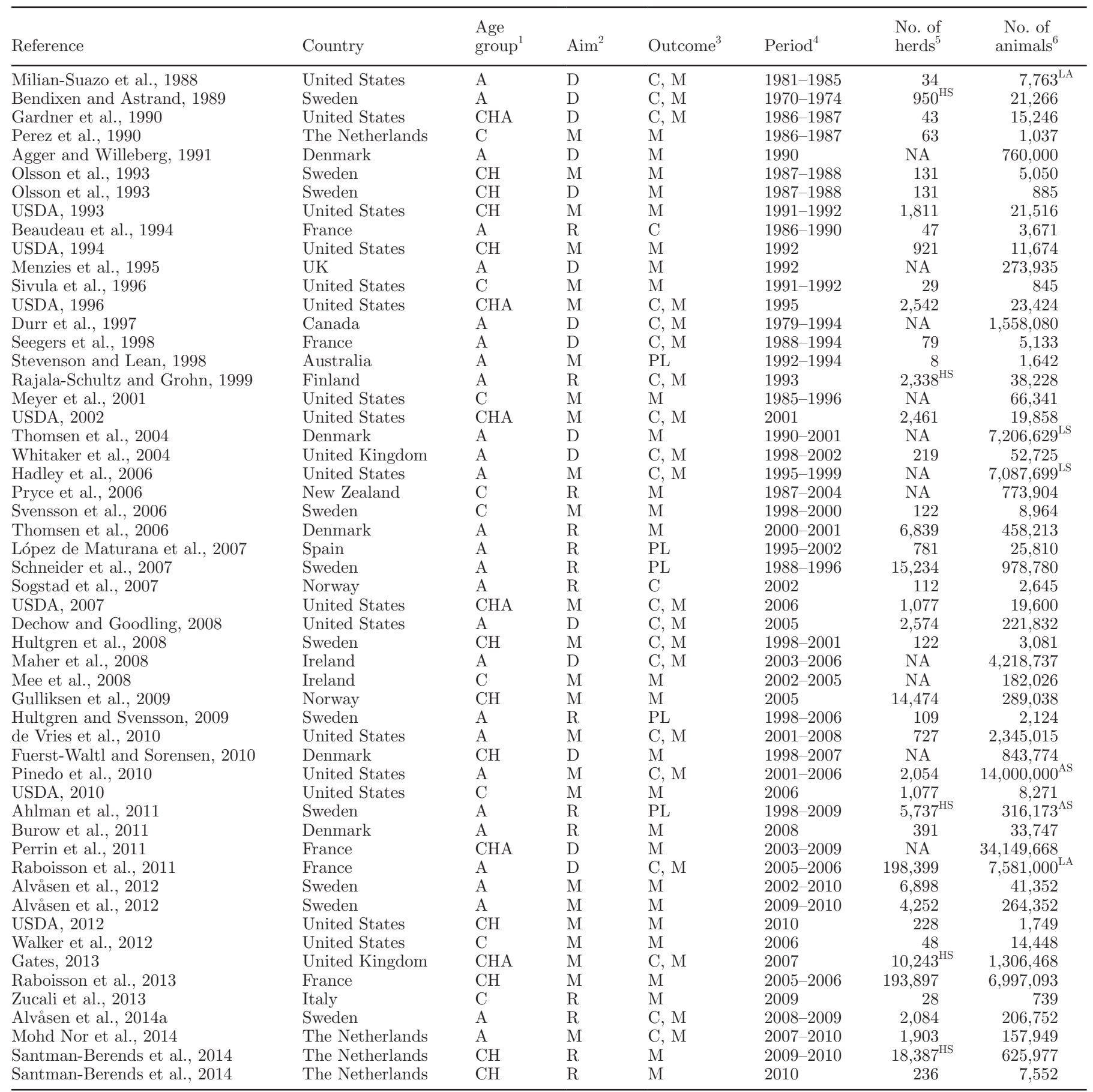

${ }^{1} \mathrm{~A}=$ adult cows (calved at least once), $\mathrm{H}=$ heifers (age period from weaning to first calving), $\mathrm{C}=$ calves (age period from birth to weaning); multiple letters denote a combination of ages.

${ }^{2}$ Main study aim: $\mathrm{D}=$ descriptive, $\mathrm{R}=$ risk factor analysis, $\mathrm{M}=$ mixed.

${ }^{3}$ Main study outcomes measured: $\mathrm{C}=$ culling, $\mathrm{M}=$ mortality, $\mathrm{PL}=$ productive life.

${ }^{4}$ Data collection period.

${ }^{5}$ Number of herds analyzed; superscript HS denotes number of herds selected for the study where the number analyzed was not stated; NA = not available.

${ }^{6}$ Number of animals analyzed; superscript AS denotes number of animals selected, superscript LA denotes number of lactations analyzed, superscript LS denotes number of lactations selected; NA = not available. 
studies were identified from diagnostic plots and by determining whether model coefficients changed by more than $15 \%$ when the study was removed from analysis. Final meta-regression models were used to predict mean effects of any retained moderator variables and their 95\% confidence intervals, and added to forest plots. Funnel plots of the transformed proportion against the standard error of each model were investigated for asymmetry, which might have been evidence of missing studies due to publication bias (Egger et al., 1997) and heterogeneity among studies (Egger and Davey Smith, 1998). Meta-regression was undertaken only when at least 5 studies had the same outcome and measure, and among the same age or parity group, to reduce the risk of unreliable estimates.

\section{RESULTS}

\section{Description of Articles and Studies}

From 3,275 articles retrieved by electronic database and manual searching, $4 \%(\mathrm{n}=118)$ were assessed as po- tentially relevant from the primary screening. Of those, $53 \%(\mathrm{n}=63)$ were appraised as eligible for inclusion in the review from the secondary screening. A further $19 \%$ of articles $(\mathrm{n}=12)$ did not have, or their authors could not provide, suitable data for meta-analysis. The final review set consisted of 51 articles reporting 54 studies (Figure 1). A total of 34 and 26 studies reported on findings of cows and calves or nulliparous heifers (or both calves and nulliparous heifers), respectively. Culling and mortality were measured in 22 and 47 studies, respectively, whereas 5 studies reported LPL. The main characteristics of reviewed studies, ordered by year of publication, are summarized in Table 2 .

\section{Assessment of Risk of Bias}

The risk of bias in the results from each of the studies included in the review was assessed as low from each of the following: selection of the source population and sampling methods ( $80 \%$ of studies), definition of outcome variables (96\% of studies), measurement of the outcome variables (96\% of studies), and meth-

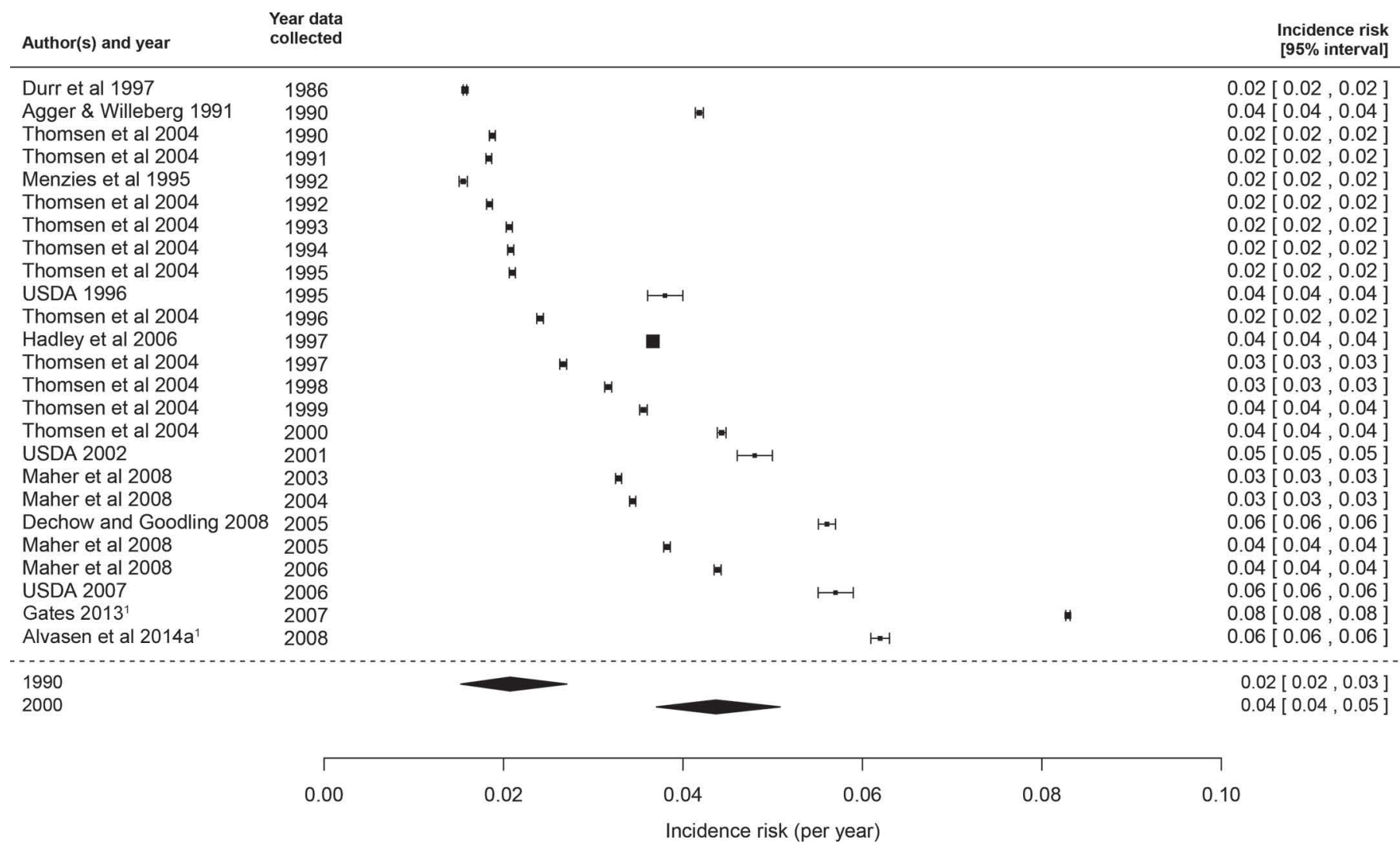

Figure 2. Annual incidence risk (ם) and 95\% CI of mortality of cows in studies included in the meta-analysis (point estimates plotted in proportion to their precision). Predicted annual incidence risk and $95 \%$ CI $(\bullet)$ of mortality at different levels of moderator variables from the meta-regression model are plotted below the dashed line. ${ }^{1}$ Results measured per lactation. 


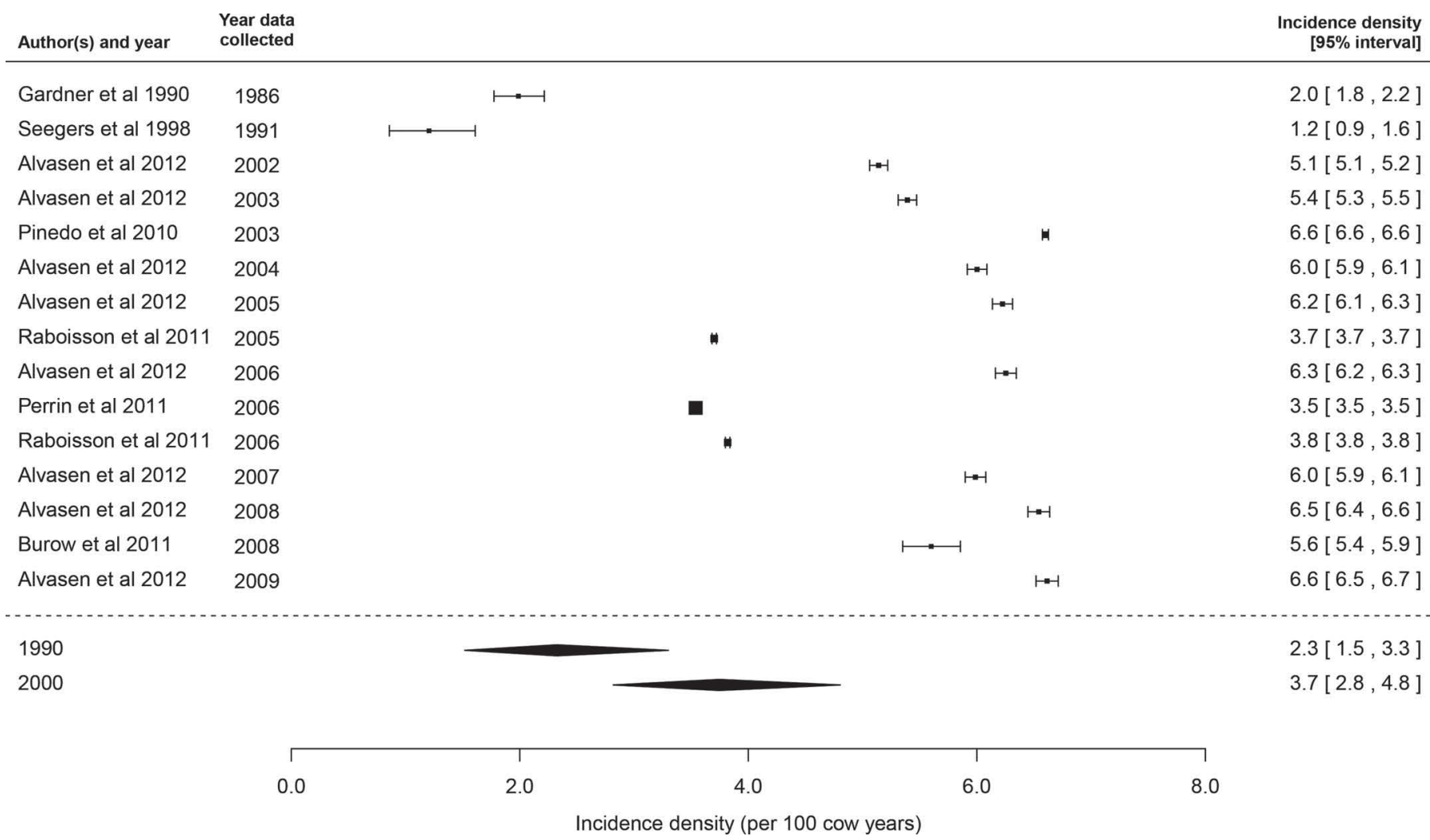

Figure 3. Incidence density ( $)$ and $95 \%$ CI of mortality in cows in studies included in the meta-analysis (point estimates plotted in proportion to their precision). Predicted incidence density and $95 \%$ CI $(\diamond)$ of mortality at different levels of moderator variables from the metaregression model are plotted below the dashed line.

ods of statistical analysis (84\% of studies), as shown in Supplemental Table S2 (https://doi.org/10.3168/ jds.2016-11302).

\section{Meta-Analyses and Meta-Regressions}

Tests for residual heterogeneity (Cochran's $Q$ test) of meta-analysis in all final models were highly significant $(P<0.001)$ in all instances, indicating significant variation among studies that was not accounted for by the moderator variables. Therefore, no summary measures were reported. There was no indication of publication bias from visual examination of funnel plots of all final models (not shown), although the usefulness of this assessment was limited by the heterogeneity among studies.

Adult Cows. In total, 25 study-years were available for evaluation of the annual IR of mortality in adult cows. Figure 2 indicates a range of annual IR of mortality between approximately 0.02 and 0.08 , and an apparent increase over time. The final MR model predicted that the annual IR of mortality of cows increased in the decade between 1990 and 2000 by an absolute 0.02 . Similarly, the ID of mortality of cows was predicted to have increased in the same period by 1.42 cases per 100 cow-years (Figure 3).

The annual IR of culling varied between 0.14 and 0.28 , and no evidence of overall change in IR over time was apparent in the forest plot (Figure 4). No inferences were made from a meta-regression model of the annual IR of culling because one study (Gates, 2013) was influential. Similarly, the results from studies that combined the IR of different outcomes revealed no discernible change over time (Figure 5). The effect of year of data collection was not significant in the MR models for culling and mortality, or for culling, mortality, and sale combined ( $P=0.085$ and $P=0.678$, respectively).

Forest plots of the study results of annual IR of culling of adult cows attributed to categories of causes revealed a decrease in IR of culling for "production," but no change for the categories for "reproduction" and "udder-related" causes (Figure 6). The annual IR of culling attributed to lower production was predicted to have decreased between 1990 and 2000 by 0.02 ( $P$ $<0.001)$.

Insufficient studies reported mean $(\mathrm{n}=3)$ or median LPL $(n=2)$ as an outcome for meta-analysis. Stevenson and Lean (1998), López de Maturana et al. (2007), 
and Ahlman et al. (2011) reported mean LPL of 1,418, 786, and 1,111 d, respectively, whereas Schneider et al. (2007) and Hultgren and Svensson (2009) reported median LPL of 640 and $780 \mathrm{~d}$, respectively.

Calves and Heifers. The IR of perinatal mortality varied from 0.03 to 0.09 (Figure 7) and was predicted to have increased between 1990 and 2000 by an absolute 0.02 . The range of reported IR of neonatal mortality varied between 0.05 and 0.11 (Figure 8 ) but did not change over time $(P=0.618)$. Diarrhea was the most frequently recorded cause of neonatal mortality in 4 studies from the United States (Gardner et al., 1990; USDA, 1993, 1996, 2002): the IR of neonatal mortality attributed to diarrhea varied from 0.02 to 0.03 .

\section{DISCUSSION}

\section{Increased Incidence of Mortality in Cows}

Results of our MA-MR indicate that previously published reports of increased IR and ID of mortality of cows in a small number of countries are, in fact, widespread in modern dairy production systems. The magnitude of change was less for the measure of ID than for IR, but this was likely due to the studies of Perrin et al. (2011) and Raboisson et al. (2011), which were conducted in a different country (France) from those that reported IR and that, in large populations, weighted the predicted change over time toward their results. Our findings are in agreement with the direction of the multi-year studies included in this review but greater in magnitude. Thomsen et al. (2004) indicated that lactational mortality IR had increased from $2 \%$ in 1990 to $3.5 \%$ in 1999 in Danish cows, and Alvåsen et al. (2012) reported a change in the ID of mortality in Swedish cows over the period from 2002 to 2010 of 5.1 to 6.6 events per 100 cow-years. Perrin et al. (2011) also reported that mortality ID had increased in French dairy cows between 2003 and 2009 on the order of an absolute 2 to 4 cases per 100 cow-years, depending on cow age. Increased IR and ID of mortality in cows in recent decades adds weight to the call for greater focus on this problem by the international dairy industry. Control schemes are required not only to reduce the economic and animal welfare costs this change has caused, but also to manage the reputational risk posed

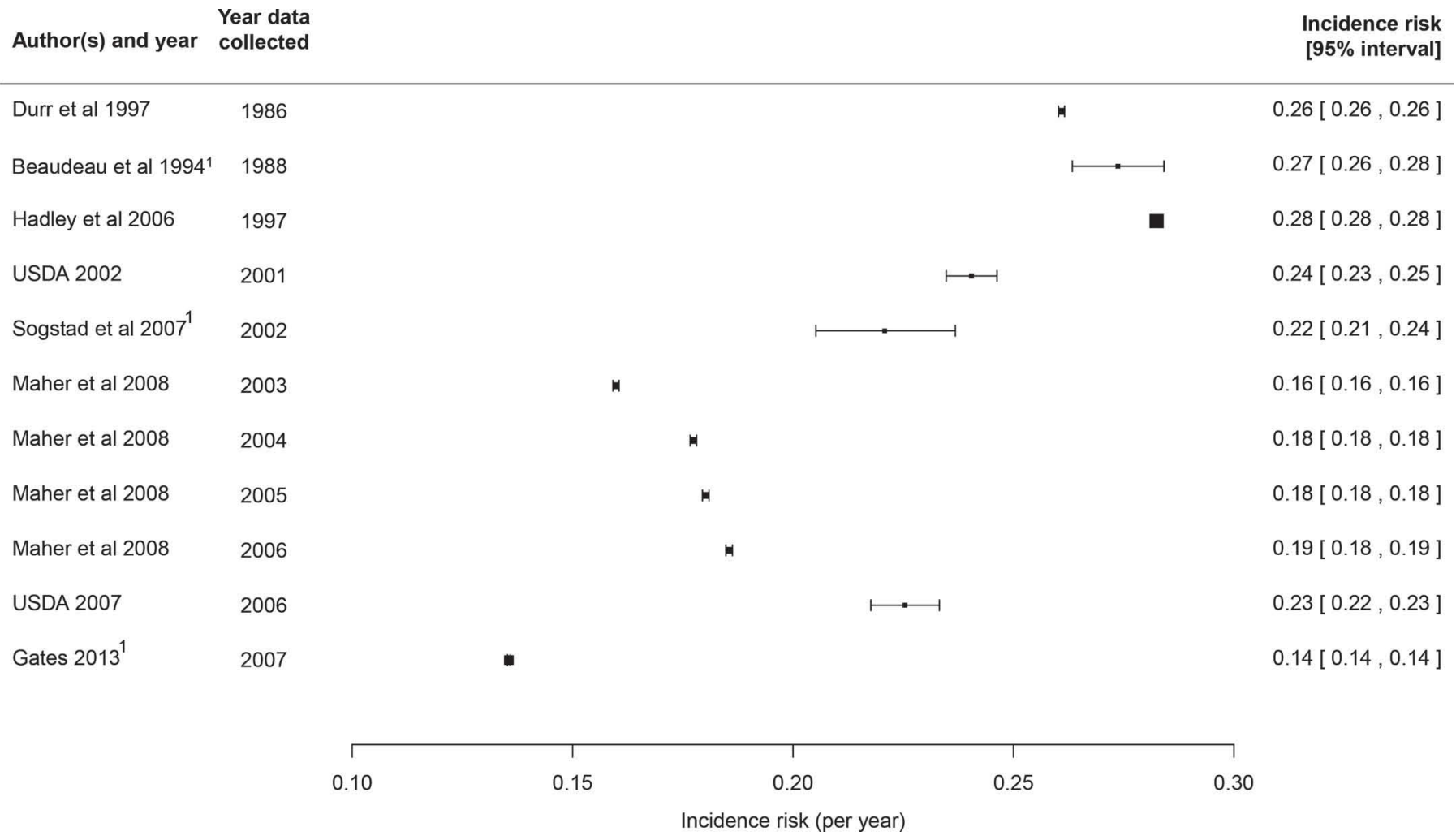

Figure 4. Annual incidence risk and $95 \%$ CI of culling of cows in studies included in the meta-analysis (point estimates plotted in proportion to their precision). ${ }^{1}$ Results measured per lactation. 


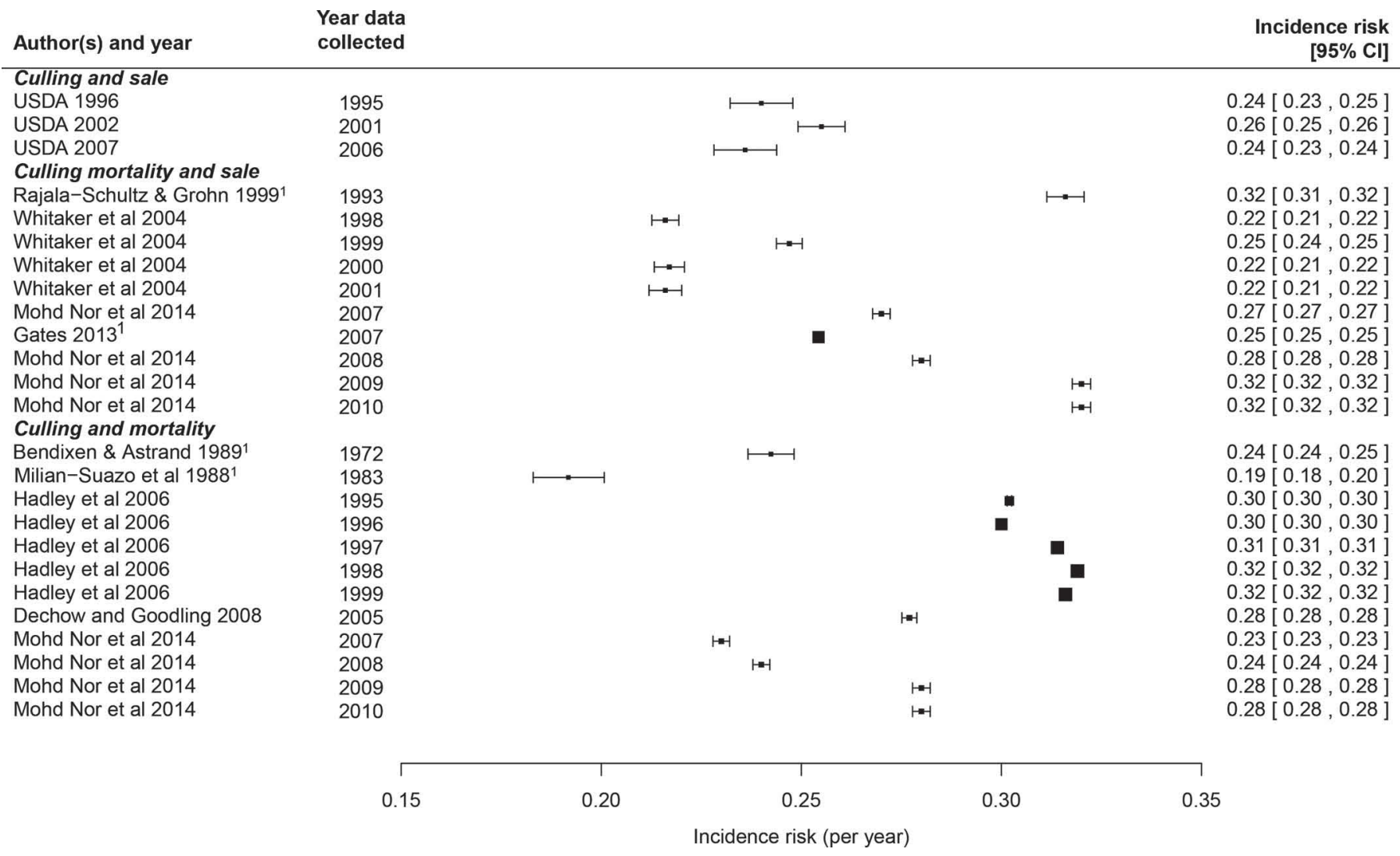

Figure 5. Annual incidence risk (ם) and 95\% CI of culling and sale; culling, mortality and sale; and culling and sale in cows in studies included in the meta-analysis (point estimates plotted in proportion to their precision). ${ }^{1}$ Results measured per lactation.

to dairy industries by this change. This task is urgent, as we currently know of no reports of programs that have successfully controlled mortality in dairy cows.

Our findings of increased IR and ID of mortality in cows are associations with time and, in themselves, are not causal. Other, off-farm changes in the regulatory, social, and commercial environments in some countries may have contributed in part to these recorded changes but were not considered in the current study. For example, changes in the regulations for emergency slaughter of defective stock (Alvåsen et al., 2012) and increased concern about investigation by authorities of possible animal welfare violations if even slightly defective animals are sent for slaughter (Thomsen and Sorensen, 2008) may have contributed to the overall increase in recorded IR or ID of mortality of cows. We were unable to investigate possible associations between production system characteristics and incidence of mortality (or culling) because data on those factors was often unavailable, and because of the small number of studies for some MR. However, this analysis might be possible in the future, if more studies with the necessary data become available.

\section{No Change in the Incidence Risk of Culling of Cows}

We found no indication of overall change in the annual IR of culling of cows in countries with modern dairy systems over the period of data collection for this outcome (1986 to 2007). Few studies have reported data collected from more than 1 year. Of those that did, Maher et al. (2008) reported that the IR of culling in Irish cows had increased, but conversely, 2 studies with longitudinal data that were aggregated in our analysis, indicated the reverse: Durr et al. (1997) reported that annual IR of culling had decreased by an absolute $4 \%$ between 1981 and 1994 among cows in Quebec, Canada, and Pinedo et al. (2010) reported that the ID of culling had decreased from 30 to 25 per 100 cow-years among eastern United States herds between 2001 and 2006. Further evidence for lack of change in the IR of culling of cows, at least in the United States, comes from 2 studies that used similar designs (USDA, 2002, 2007) and reported almost no change between 2001 and 2006. Reasons for the inconsistent patterns of change and single-year results between studies were not determined in the current study, but we speculate that other factors 
associated with culling, such as characteristics of the production systems, economic conditions, or individual herds (Beaudeau et al., 2000; Hadley et al., 2006) also varied between study populations and over the years of data collection.

\section{Decreased Incidence Risk of Culling Attributed to Poor Production}

We found that over approximately 2 decades from the mid 1980s, the annual IR of culling for production-related reasons decreased, whereas that for reproduction- and udder-related causes was unchanged. This finding is supported by Durr et al. (1997), who reported that the annual IR for culling attributed to poor production had decreased from $17 \%$ in 1981 to $4 \%$ in 1994. It is commonly believed that to maintain or improve herd productivity, farmers will make an economic decision to cull cows with poor milk production and replace them with more productive cows. However, our findings indicate that farmers have been increasingly constrained from doing this. Reasons for this are unclear from our data, but may be associated with a change toward other disease-related reasons for culling, such as lameness or injury, that were not categorized in such a way to make them available for this MA-MR. It is likely that improving production efficiency will continue to be an objective of dairy farmers; therefore, discovery and implementation of practices to reverse reduction in culling because of low production should be an objective of research and extension.

\section{Increased Perinatal But Not Neonatal Calf Mortality}

Fewer studies were available from studies on calves, and what was available could often not be fully utilized because there were too few studies using the same or similar age range categories to allow comparisons. Nevertheless, sufficient data were available for MA-MR of IR of perinatal and neonatal mortality. Estimates of the IR of perinatal mortality (born full-term but died before 1 or $2 \mathrm{~d}$ of age) varied between studies, but this is not unexpected because of the difficulties and various methods used to record these cases. For example, the upper age limit used to define the period at risk was either 1 or $2 \mathrm{~d}$. The practical effect of

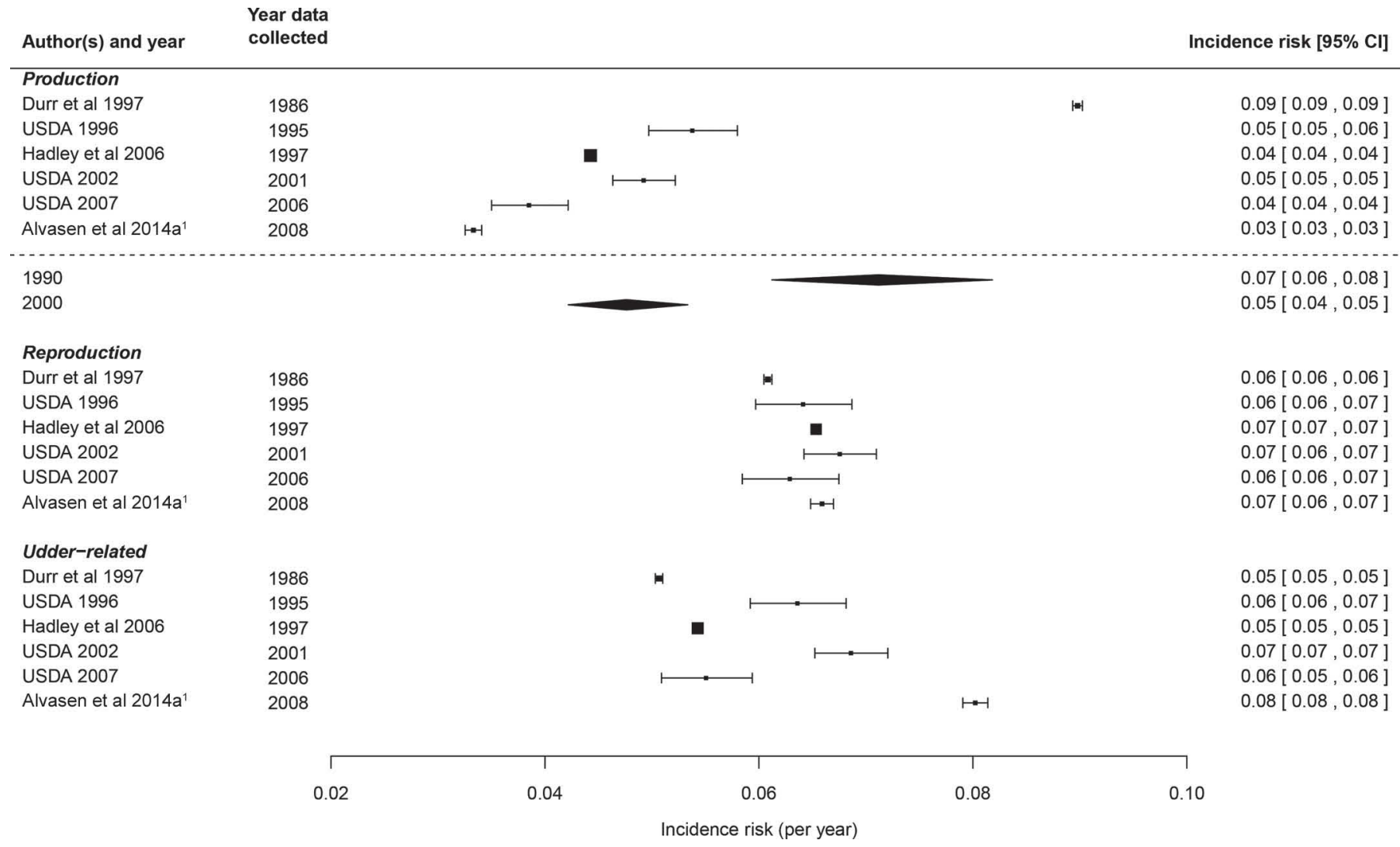

Figure 6. Annual incidence risk ( $)$ and 95\% CI of culling of adult cows grouped by attributed cause category in studies included in the meta-analysis (point estimates plotted in proportion to their precision). Predicted annual incidence risk and $95 \%$ CI ( $\bullet$ ) of culling at different levels of moderator variables from the meta-regression models are plotted below the dashed line. ${ }^{1}$ Results measured per lactation. 
this is unclear, but use of the higher limit $(2 \mathrm{~d})$ would presumably be reflected in higher mortality estimates because of increased time at risk. It is also likely that perinatal mortality is incompletely recorded because not all calves are registered by farmers, and the loss of these records would result in an underestimation of perinatal mortality. Notwithstanding these difficulties, we estimated by MR that the IR of perinatal mortality increased by an absolute 0.02 between 1990 and 2000. An increase in the IR of perinatal mortality over time was also reported by Mee et al. (2008), but the causes for the change were not explained by known risk factors, such as age of the dam, degree of calving difficulty, or gestational age. Increased perinatal mortality in modern dairy countries reduces production efficiency by reducing availability of calves to act as replacements or for sale and additionally incurs welfare costs. We are unaware of control programs for perinatal mortality, and we urge further efforts for that purpose.

In contrast, we found no evidence that the IR of neonatal mortality had increased in the 2 decades from 1990. The most commonly attributed causes of mortality in this age group, as reported in other studies, were enteritis and pneumonia. Nevertheless, mortality in this age group represents an important financial loss to dairy farmers and again, reflects poorly on the welfare status of this age group. Consequently, the status quo is not desirable, and control programs that instead reduce mortality in neonatal calves would be valuable to farmers.

\section{Bias}

The possibility and consequences of bias should be considered in this as with all systematic reviews. Twelve articles were excluded from the review because requested data were not supplied or because the authors could not be contacted or did not respond. We received fewer responses, and fewer responses with data, following requests to the authors of articles published before the year 2000. Although these problems were unavoidable, they may have biased selection toward more recently published articles. However, the overall risk of bias assessed in the reviewed studies was low. Despite this, it is probable that the usual forms of bias in data from observational studies also exist in these data, such

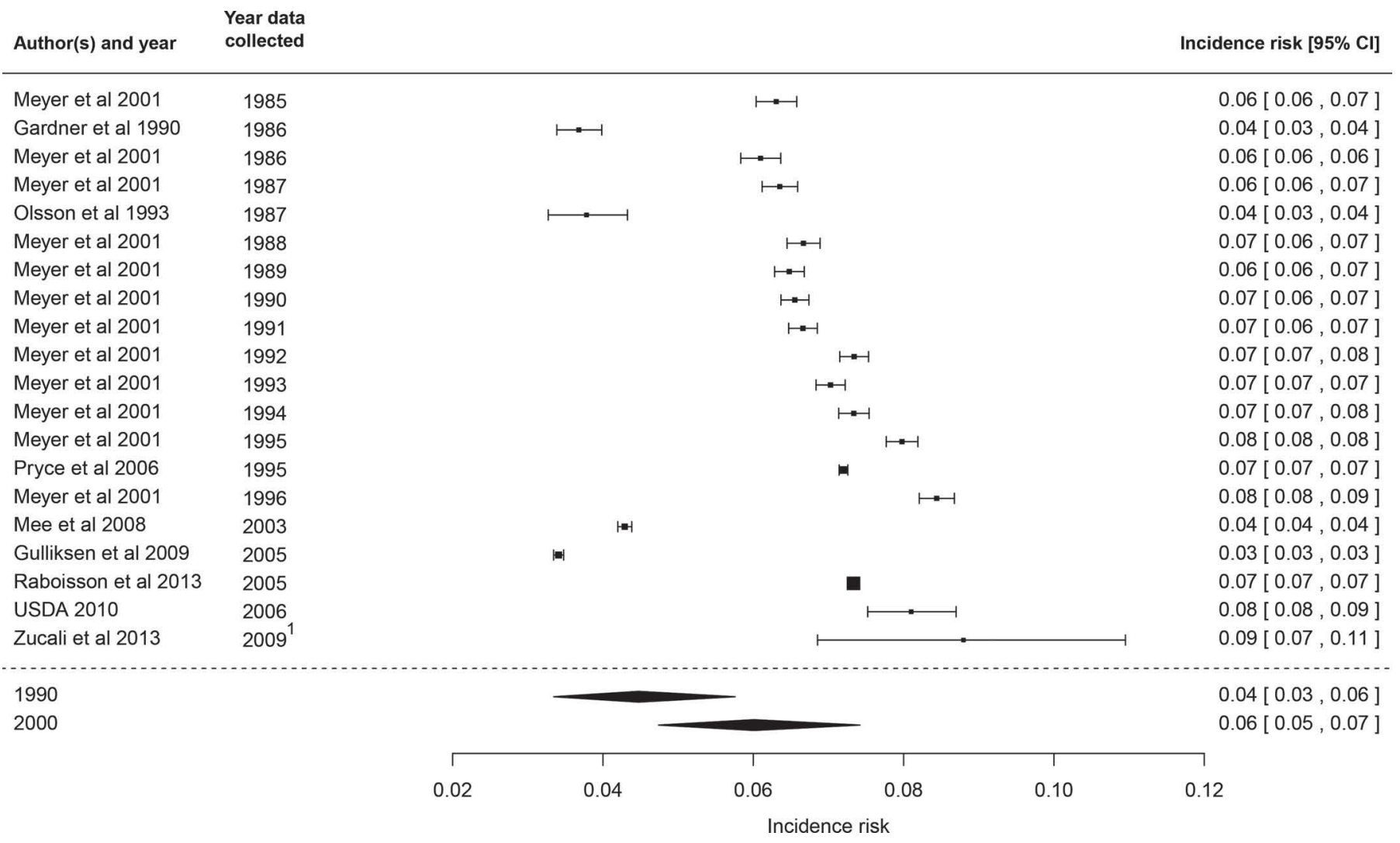

Figure 7. Incidence risk ( $)$ and $95 \%$ CI of perinatal mortality (full-term birth to $2 \mathrm{~d}$ of age) in studies included in the meta-analysis (point estimates plotted in proportion to their precision). Predicted incidence risk and 95\% CI ( ) of mortality at different levels of moderator variables from the meta-regression models are plotted below the dashed line. ${ }^{1}$ Female calves only. 


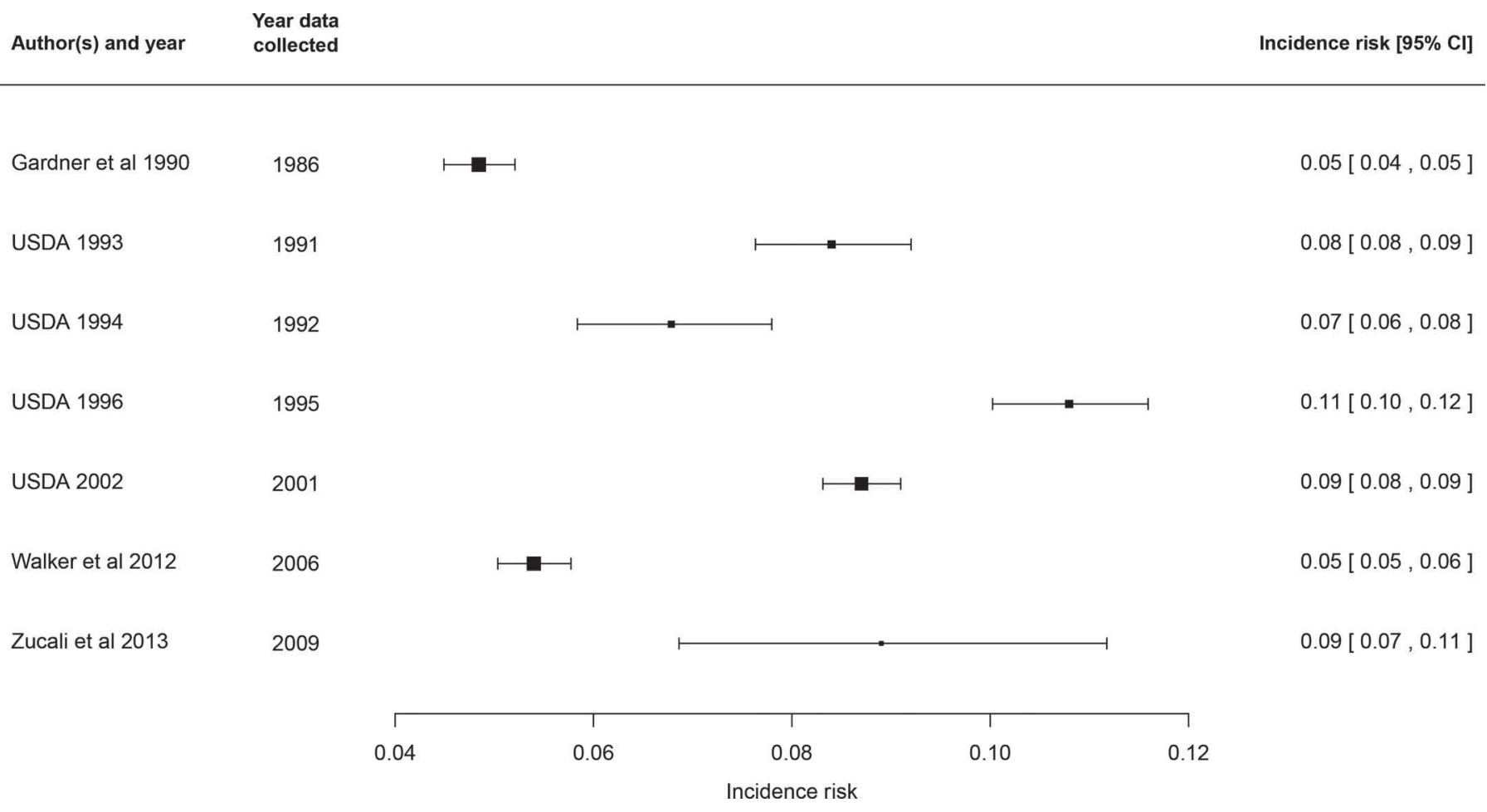

Figure 8. Incidence risk ( $)$ and $95 \%$ CI of neonatal mortality ( $1 \mathrm{~d}$ of age to weaning) in studies included in the meta-analysis (point estimates plotted in proportion to their precision).

as information bias due to inaccurate and incomplete records, particularly of the previously mentioned risk of misclassification of sold animals when they may have been culled for slaughter, and farmer-attributed causes of culling and mortality. Explicit mention of data validation was reported in $24 \%$ of studies and, of those, in only 2 of the 29 studies that used secondary data. The direction and extent to which these biases affected the results in the reviewed studies is unknown and seldom commented on by the authors but should be considered when interpreting the findings of this review. We further investigated, by sensitivity analysis, the possibility that studies that reported multiple years of data were influential in the MR models, but this was not found to be the case, as the magnitude and direction of the coefficients were robust to removing these studies individually or entirely from the models. In only 1 of the 3 models did the $P$-value become nonsignificant $(P=$ $0.11)$.

\section{Nomenclature}

Several features of articles reduced the number of results available for MA-MR. For example, the definitions of outcomes involving culling and mortality have varied in the $25 \mathrm{yr}$ of publication that the selected articles spanned, which increased the number of outcomes reported and reduced the number available for each comparison. A review article by Fetrow et al. (2006) recommended a 2-level system to code animal removal events: first the destination or fate, and then the attributed reason. They and previous authors (Dohoo and Dijkhuizen, 1993; Radke, 2000) argued to distinguish the cause of culling as either "biological" (also known as "forced") or "economic." Biological culls are those animals without a possible productive future; for example, permanently infertile or irreparably injured, whereas economic culls are those that will be replaced with a more profitable animal. We agree with these authors' recommendations and, furthermore, suggest that different destinations for cow disposals be reported separately to preserve information for use by researchers in other countries who use different definitions for culling. Additionally, we recommend that farmers record euthanized animals to distinguish these animals from those that die unassisted, as has been instituted in some European countries, such as Denmark and Sweden (Thomsen et al., 2004; Alvåsen et al., 2012). Similarly, we recommend a reduced and standardized range of categories for reasons attributed to mortality and culling. Two examples of categorization schemes that are simple and provide meaningful information are those used by the USDA in the National Animal Health Monitoring Scheme, which uses 7 categories 
(not including death) for culling: udder/mastitis, reproduction, lameness/injury, poor production unrelated to other disease, other disease, behavior, and unspecified; and that of Thomsen and Houe (2006), who used 8 categories for mortality: accident, calving, digestive, locomotor, metabolic, udder/teat, other known, and unknown causes. Together, implementation of these suggested changes would enhance the reporting and understanding of mortality and culling of dairy animals.

\section{ACKNOWLEDGMENTS}

This work was funded by New Zealand dairy farmers through DairyNZ Inc. (Hamilton, New Zealand; project number RD1405) and by the Ministry of Business, Innovation and Employment (Wellington, New Zealand) through the research partnership "Pillars of a Competitive and Responsible Dairy System: Improved Longevity and Reproductive Performance" (contract number DRCX1302). We thank the authors of the reviewed articles, who when asked for further data or clarification, responded, even if requested data were no longer available, and sometimes went to considerable lengths to retrieve records.

\section{REFERENCES}

Agger, J., and P. Willeberg. 1991. Production and mortality in dairy cows from 1960-1990: Time series analysis of ecological data. Pages 357-360 in Proc. 6th Int. Symp. Vet. Epidemiol. Econ., Ottawa, Canada.

Ahlman, T., B. Berglund, L. Rydhmer, and E. Strandberg. 2011. Culling reasons in organic and conventional dairy herds and genotype by environment interaction for longevity. J. Dairy Sci. 94:1568 1575. http://dx.doi.org/10.3168/jds.2010-3483.

Alvåsen, K., M. Jansson Mörk, I. R. Dohoo, C. H. Sandgren, P. T Thomsen, and U. Emanuelson. 2014a. Risk factors associated with on-farm mortality in Swedish dairy cows. Prev. Vet. Med. 117:110120. http://dx.doi.org/10.1016/j.prevetmed.2014.08.011.

Alvåsen, K., M. J. Mork, C. H. Sandgren, P. T. Thomsen, and U. Emanuelson. 2012. Herd-level risk factors associated with cow mortality in Swedish dairy herds. J. Dairy Sci. 95:4352-4362. http://dx.doi.org/10.3168/jds.2011-5085.

Alvåsen, K., A. Roth, M. Jansson Mork, C. Hallen Sandgren, P. T. Thomsen, and U. Emanuelson. 2014b. Farm characteristics related to on-farm cow mortality in dairy herds: A questionnaire study. Animal 8:1735-1742. http://dx.doi.org/10.1017/S1751731114001633.

Beaudeau, F., K. Frankena, C. Fourichon, H. Seegers, B. Faye, and J. P. T. M. Noordhuizen. 1994. Associations between health disorders of French dairy cows and early and late culling within the lactation. Prev. Vet. Med. 19:213-231. http://dx.doi.org/10.1016/01675877(94)90090-6.

Beaudeau, F., H. Seegers, V. Ducrocq, C. Fourichon, and N. Bareille. 2000. Effect of health disorders on culling in dairy cows: A review and critical discussion. Ann. Zootech. 49:293-311. http://dx.doi. org/10.1051/animres:2000102.

Bendixen, P. H., and D. B. Astrand. 1989. Removal risks in Swedish Friesian dairy-cows according to parity, stage of lactation, and occurrence of clinical mastitis. Acta Vet. Scand. 30:37-42.

Burow, E., P. T. Thomsen, J. T. Sorensen, and T. Rousing. 2011. The effect of grazing on cow mortality in Danish dairy herds. Prev. Vet. Med. 100:237-241. http://dx.doi.org/10.1016/j. prevetmed.2011.04.001.
De Vries, A., J. D. Olson, and P. J. Pinedo. 2010. Reproductive risk factors for culling and productive life in large dairy herds in the eastern United States between 2001 and 2006. J. Dairy Sci. 93:613-623. http://dx.doi.org/10.3168/jds.2009-2573.

de Vries, M., E. A. M. Bokkers, T. Dijkstra, G. van Schaik, and I. J. M. de Boer. 2011. Invited review: Associations between variables of routine herd data and dairy cattle welfare indicators. J. Dairy Sci. 94:3213-3228. http://dx.doi.org/10.3168/jds.2011-4169.

Dechow, C. D., and R. C. Goodling. 2008. Mortality, culling by sixty days in milk, and production profiles in high- and low-survival Pennsylvania herds. J. Dairy Sci. 91:4630-4639. http://dx.doi. org/10.3168/jds.2008-1337.

Dohoo, I., W. Martin, and H. Stryhn. 2009. Veterinary Epidemiologic Research. 2nd ed. Atlantic Veterinary College Inc., Charlottetown, Canada.

Dohoo, I. R., and A. A. Dijkhuizen. 1993. Techniques involved in making dairy-cow culling decisions. Compend. Contin. Educ. Pract. Vet. 15:515-519.

Durr, J. W., H. G. Monardes, R. I. Cue, and J. C. Philpot. 1997. Culling in Quebec Holstein herds. 2. Study of phenotypic trends in reasons for disposal. Can. J. Anim. Sci. 77:601-608. http://dx.doi. org/10.4141/A96-132.

Egger, M., and G. Davey Smith. 1998. Meta-analysis: Bias in location and selection of studies. BMJ 316:61-66.

Egger, M., M. Schneider, and G. D. Smith. 1998. Meta-analysisSpurious precision? Meta-analysis of observational studies. BMJ 316:140-144. http://dx.doi.org/10.1136/bmj.316.7125.140.

Egger, M., G. D. Smith, M. Schneider, and C. Minder. 1997. Bias in meta-analysis detected by a simple, graphical test. BMJ 315:629634.

FAO, IDF, and IFCN. 2014. World Mapping of Animal Feeding Systems in the Dairy Sector. Food and Agriculture Organization of the United Nations (FAO), International Dairy Federation (FILIDF; Brussels, Belgium), IFCN Dairy Research Network (Kiel, Germany). FAO, Rome, Italy.

Fetrow, J., K. V. Nordlund, and H. D. Norman. 2006. Invited review: Culling: Nomenclature, definitions, and recommendations. J. Dairy Sci. 89:1896-1905. http://dx.doi.org/10.3168/jds.S00220302(06) 72257-3

Freeman, M. F., and J. W. Tukey. 1950. Transformations related to the angular and the square root. Ann. Math. Stat. 21:607-611. http://dx.doi.org/10.1214/aoms/1177729756.

Fuerst-Waltl, B., and M. K. Sorensen. 2010. Genetic analysis of calf and heifer losses in Danish Holstein. J. Dairy Sci. 93:5436-5442. http://dx.doi.org/10.3168/jds.2010-3227.

Gardner, I. A., D. W. Hird, W. W. Utterback, C. Danayeelmi, B. R. Heron, K. H. Christiansen, and W. M. Sischo. 1990. Mortality, morbidity, case-fatality, and culling rates for California dairycattle as evaluated by the National Animal Health MonitoringSystem, 1986-87. Prev. Vet. Med. 8:157-170. http://dx.doi. org/10.1016/0167-5877(90)90008-6.

Gates, M. C. 2013. Evaluating the reproductive performance of British beef and dairy herds using national cattle movement records. Vet. Rec. 173:499 http://dx.doi.org/10.1136/vr.101488.

Grindlay, D. J. C., M. L. Brennan, and R. S. Dean. 2012. Searching the veterinary literature: A comparison of the coverage of veterinary journals by nine bibliographic databases. J. Vet. Med. Educ. 39:404-412. http://dx.doi.org/10.3138/jvme.1111.109R.

Gulliksen, S. M., K. I. Lie, T. Løken, and O. Østerås. 2009. Calf mortality in Norwegian dairy herds. J. Dairy Sci. 92:2782-2795. http://dx.doi.org/10.3168/jds.2008-1807.

Hadley, G. L., C. A. Wolf, and S. B. Harsh. 2006. Dairy cattle culling patterns, explanations, and implications. J. Dairy Sci. 89:22862296. http://dx.doi.org/10.3168/jds.S0022-0302(06)72300-1.

Hedges, L. V., and J. L. Vevea. 1998. Fixed- and random-effects models in meta-analysis. Psychol. Methods 3:486-504. http://dx.doi org/10.1037/1082-989X.3.4.486.

Hultgren, J., and C. Svensson. 2009. Heifer rearing conditions affect length of productive life in Swedish dairy cows. Prev. Vet. Med. 89:255-264. http://dx.doi.org/10.1016/j.prevetmed.2009.02.012. 
Hultgren, J., C. Svensson, D. O. Maizon, and P. A. Oltenacu. 2008. Rearing conditions, morbidity and breeding performance in dairy heifers in southwest Sweden. Prev. Vet. Med. 87:244-260. http:// dx.doi.org/10.1016/j.prevetmed.2008.04.003.

Konstantopoulos, S. 2011. Fixed effects and variance components estimation in three-level meta-analysis. Res. Synth. Methods 2:61-76. http://dx.doi.org/10.1002/jrsm.35.

López de Maturana, E., E. Ugarte, and O. Gonzalez-Recio. 2007. Impact of calving ease on functional longevity and herd amortization costs in Basque Holsteins using survival analysis. J. Dairy Sci. 90:4451-4457. http://dx.doi.org/10.3168/jds.2006-734.

Maher, P., M. Good, and S. J. More. 2008. Trends in cow numbers and culling rate in the Irish cattle population, 2003 to 2006. Ir. Vet. J. 61:455-463. http://dx.doi.org/10.1186/2046-0481-61-7-455.

Mee, J. F., D. P. Berry, and A. R. Crornie. 2008. Prevalence of, and risk factors associated with, perinatal calf mortality in pasturebased Holstein-Friesian cows. Animal 2:613-620. http://dx.doi. org/10.1017/S1751731108001699.

Menzies, F. D., D. G. Bryson, T. McCallion, and D. I. Matthews. 1995. A study of mortality among suckler and dairy-cows in NorthernIreland in 1992. Vet. Rec. 137:531-536. http://dx.doi.org/10.1136/ vr.137.21.531.

Meyer, C. L., P. J. Berger, K. J. Koehler, J. R. Thompson, and C G. Sattler. 2001. Phenotypic trends in incidence of stillbirth for Holsteins in the United States. J. Dairy Sci. 84:515-523. http:// dx.doi.org/10.3168/jds.S0022-0302(01)74502-X.

Milian-Suazo, F., H. N. Erb, and R. D. Smith. 1988. Descriptive epidemiology of culling in dairy-cows from 34 herds in New-York State. Prev. Vet. Med. 6:243-251. http://dx.doi.org/10.1016/01675877(88)90036-0.

Mohd Nor, N., W. Steeneveld, and H. Hogeveen. 2014. The average culling rate of Dutch dairy herds over the years 2007 to 2010 and its association with herd reproduction, performance and health. J. Dairy Res. 81:1-8. http://dx.doi.org/10.1017/S0022029913000460.

O'Connor, A., and J. Sargeant. 2015. Research synthesis in veterinary science: Narrative reviews, systematic reviews and meta-analysis Vet. J. 206:261-267. http://dx.doi.org/10.1016/j.tvjl.2015.08.025.

O'Connor, A. M., and J. M. Sargeant. 2014. An introduction to systematic reviews in animal health, animal welfare, and food safety. Anim. Health Res. Rev. 15:3-13. http://dx.doi.org/10.1017/ S146625231400005X

Olsson, S. O., S. Viring, U. Emanuelsson, and S. O. Jacobsson. 1993. Calf diseases and mortality in Swedish dairy herds. Acta Vet. Scand. 34:263-269.

Perez, E., J. Noordhuizen, L. A. Vanwuijkhuise, and E. N. Stassen. 1990. Management factors related to calf morbidity and mortalityrates. Livest. Prod. Sci. 25:79-93. http://dx.doi.org/10.1016/03016226(90)90043-6.

Perrin, J. B., C. Ducrot, J. L. Vinard, P. Hendrikx, and D. Calavas. 2011. Analysis of cattle mortality in France, 2003-2009. Prod. Anim. 24:235-244.

Pinedo, P. J., A. De Vries, and D. W. Webb. 2010. Dynamics of culling risk with disposal codes reported by Dairy Herd Improvement dairy herds. J. Dairy Sci. 93:2250-2261. http://dx.doi. org/10.3168/jds.2009-2572.

Pryce, J. E., B. L. Harris, S. Sim, and A. W. McPherson. 2006. Genetics of stillbirth in dairy calves. Pages 98-102 in Proc. New Zealand Soc. Anim. Prod., Napier, New Zealand.

Raboisson, D., E. Cahuzac, P. Sans, and G. Allaire. 2011. Herd-level and contextual factors influencing dairy cow mortality in France in 2005 and 2006. J. Dairy Sci. 94:1790-1803. http://dx.doi. org $/ 10.3168 /$ jds.2010-3634.

Raboisson, D., F. Delor, E. Cahuzac, C. Gendre, P. Sans, and G. Allaire. 2013. Perinatal, neonatal, and rearing period mortality of dairy calves and replacement heifers in France. J. Dairy Sci. 96:2913-2924. http://dx.doi.org/10.3168/jds.2012-6010.

Radke, B. R. 2000. Production management: Sixteen dairy culling and replacement myths. Compend. Contin. Educ. Pract. Vet. 22:S36S57.

Rajala-Schultz, P. J., and Y. T. Grohn. 1999. Culling of dairy cows. Part I. Effects of diseases on culling in Finnish Ayrshire cows.
Prev. Vet. Med. 41:195-208. http://dx.doi.org/10.1016/S01675877(99)00046-X

Renkema, J. A., and J. Stelwagen. 1979. Economic evaluation of replacement rates in dairy herds. 1. reduction of replacement rates through improved health. Livest. Prod. Sci. 6:15-27. http://dx.doi. org/10.1016/0301-6226(79)90028-9

Rogers, G. W., J. A. M. Vanarendonk, and B. T. McDaniel. 1988 Influence of involuntary culling on optimum culling rates and annualized net revenue. J. Dairy Sci. 71:3463-3469.

Sanderson, S., L. D. Tatt, and J. P. T. Higgins. 2007. Tools for assessing quality and susceptibility to bias in observational studies in epidemiology: A systematic review and annotated bibliography. Int. J. Epidemiol. 36:666-676. http://dx.doi.org/10.1093/ije/dym018.

Santman-Berends, I. M. G. A., M. Buddiger, A. J. G. Smolenaars, C. D. M. Steuten, C. A. J. Roos, A. J. M. Van Erp, and G. Van Schaik. 2014. A multidisciplinary approach to determine factors associated with calf rearing practices and calf mortality in dairy herds. Prev. Vet. Med. 117:375-387. http://dx.doi.org/10.1016/j. prevetmed.2014.07.011

Sargeant, J. M., and M. Del Rocio Amezcua. 2005. A Guide to Conducting Systematic Reviews in Agri-Food Public Health. Government of Canada, Ottawa, ON, Canada.

Sargeant, J. M., and A. M. O'Connor. 2014. Introduction to systematic reviews in animal agriculture and veterinary medicine. Zoonoses Public Health 61(Suppl. 1):3-9. http://dx.doi.org/10.1111/ zph.12128.

Schneider, M. P., E. Strandberg, U. Emanuelson, K. Grandinson, and A. Roth. 2007. The effect of veterinary-treated clinical mastitis and pregnancy status on culling in Swedish dairy cows. Prev. Vet. Med. 80:179-192. http://dx.doi.org/10.1016/j.prevetmed.2007.02.006.

Seegers, H., F. Beaudeau, C. Fourichon, and N. Bareille. 1998. Reasons for culling in French Holstein cows. Prev. Vet. Med. 36:257-271. http://dx.doi.org/10.1016/S0167-5877(98)00093-2.

Sivula, N. J., T. R. Ames, W. E. Marsh, and R. E. Werdin. 1996 Descriptive epidemiology of morbidity and mortality in Minnesota dairy heifer calves. Prev. Vet. Med. 27:155-171. http://dx.doi. org/10.1016/0167-5877(95)01000-9.

Sogstad, A. M., O. Osteras, T. Fjeldaas, and O. Nafstad. 2007. Bovine claw and limb disorders related to culling and carcass characteristics. Livest. Sci. 106:87-95. http://dx.doi.org/10.1016/j. livsci.2006.07.003.

Stevenson, M. A., and I. J. Lean. 1998. Descriptive epidemiological study on culling and deaths in eight dairy herds. Aust. Vet. J. $\quad 76: 482-488$. http://dx.doi.org/10.1111/j.1751-0813.1998. tb10188.x.

Svensson, C., A. Linder, and S. O. Olsson. 2006. Mortality in Swedish dairy calves and replacement heifers. J. Dairy Sci. 89:4769-4777. http://dx.doi.org/10.3168/jds.S0022-0302(06)72526-7.

Thomsen, P. T., and H. Houe. 2006. Dairy cow mortality: A review. Vet. Q. 28:122-129. http://dx.doi.org/10.1080/01652176.2006.969 5218.

Thomsen, P. T., A. M. Kjeldsen, J. T. Sorensen, and H. Houe. 2004. Mortality (including euthanasia) among Danish dairy cows (19902001). Prev. Vet. Med. 62:19-33. http://dx.doi.org/10.1016/j. prevetmed.2003.09.002

Thomsen, P. T., A. M. Kjeldsen, J. T. Sorensen, H. Houe, and A. K. Ersboll. 2006. Herd-level risk factors for the mortality of cows in Danish dairy herds. Vet. Rec. 158:622-626. http://dx.doi. org/10.1136/vr.158.18.622.

Thomsen, P. T., and J. T. Sorensen. 2008. Euthanasia of Danish dairy cows evaluated in two questionnaire surveys. Acta Vet. Scand. 50:33 http://dx.doi.org/10.1186/1751-0147-50-33.

USDA. 1993. Dairy herd management practices focusing on preweaned heifers April 1991-July 1992. USDA Animal and Plant Health Inspection Service (APHIS)-Veterinary Services (VS), Riverdale, MD.

USDA. 1994. Dairy heifer morbidity, mortality, and health management focusing on preweaned heifers April 1991-July 1992. USDA Animal and Plant Health Inspection Service (APHIS)-Veterinary Services (VS), Riverdale, MD. 
USDA. 1996. Part I: Reference of 1996 dairy management practices. National Animal Health Monitoring System. USDA Animal and Plant Health Inspection Service (APHIS)-Veterinary Services (VS), Riverdale, MD

USDA. 2002. Dairy 2002 Part I: Reference of dairy health and management in the United States, 2002. National Animal Health Monitoring System, USDA Animal and Plant Health Inspection Service (APHIS)-Veterinary Services (VS), Riverdale, MD.

USDA. 2007. Dairy 2007 Part I: Reference of dairy cattle health and management practices in the United States, 2007. National Animal Health Monitoring System, USDA Animal and Plant Health Inspection Service (APHIS)-Veterinary Services (VS), Riverdale, MD.

USDA. 2010. Dairy 2007: Heifer calf health and management practices on U.S. dairy operations, 2007. National Animal Health Monitoring System, USDA Animal and Plant Health Inspection Service (APHIS)-Veterinary Services (VS), Riverdale, MD.

USDA. 2012. Dairy heifer raiser, 2011: An overview of operations that specialize in raising dairy heifers. National Animal Health Moni- toring System, USDA Animal and Plant Health Inspection Service (APHIS)-Veterinary Services (VS), Riverdale, MD.

Viechtbauer, W. 2010. Conducting meta-analyses in $\mathrm{R}$ with the metafor package. J. Stat. Softw. 36:1-48.

Walker, W. L., W. B. Epperson, T. E. Wittum, L. K. Lord, P. J. Rajala-Schultz, and J. Lakritz. 2012. Characteristics of dairy calf ranches: Morbidity, mortality, antibiotic use practices, and biosecurity and biocontainment practices. J. Dairy Sci. 95:2204-2214. http://dx.doi.org/10.3168/jds.2011-4727.

Whitaker, D. A., A. I. Macrae, and E. Burrough. 2004. Disposal and disease rates in British dairy herds between April 1998 and March 2002. Vet. Rec. 155:43-47. http://dx.doi.org/10.1136/vr.155.2.43.

Zucali, M., L. Bava, A. Tamburini, M. Guerci, and A. Sandrucci. 2013. Management risk factors for calf mortality in intensive Italian dairy farms. Ital. J. Anim. Sci. 12:162-166. http://dx.doi org/10.4081/ijas.2013.e26. 